\title{
Tropical Cyclone Larry: Estimation of wind field and assessment of building damage *
}

\author{
JD Ginger ${ }^{\dagger}$, DJ Henderson and CJ Leitch \\ Cyclone Testing Station, School of Engineering, James Cook University, Townsville \\ GN Boughton \\ TimberED Services Pty Ltd, Perth
}

\begin{abstract}
SUMMARY: Tropical Cyclone Larry made landfall on 20 March 2006 near Innisfail, causing significant damage to buildings in the surrounding areas. This paper is based on the field survey and assessment of the performance of buildings, which experienced severe winds in the Innisfail region during Tropical Cyclone Larry. The peak gust wind speeds in the study area are estimated at 50 to $65 \mathrm{~m} / \mathrm{s}$, which is less than the region's current design wind speed. Damage to the housing stock was estimated at about $20 \%$ (not including water ingress). Contemporary housing fared considerably better than older housing, reflecting marked improvement of construction detailing and better structural condition, and satisfactory performance of relevant standards. Failure of roller doors, loss of roof battens when fastened to rafters with one or two nails, and loss of rafters or trusses when anchored to top plates with skew nails only, were common. Structural component failures of under-designed cold-formed steel sheds and garages were also widespread. Construction details used in houses on or near hill-tops need to reflect the higher wind speed caused by topographic effects.
\end{abstract}

\section{INTRODUCTION}

Tropical Cyclone Larry crossed the North Queensland coast in the early morning of Monday 20 March 2006 , causing significant community disruption and inflicting severe damage to infrastructure and crops in the region of Innisfail, shown in figure 1. The Cyclone Testing Station (CTS) conducted a study to assess the performance of buildings in the areas in and around Innisfail; from Babinda in the north to Kurrimine Beach in the south. As a part of this study, the wind field (ie. speed and direction) was determined, as well as an assessment of the effectiveness of the building code and relevant standards.

\section{CHARACTERISTICS OF TROPICAL CYCLONE LARRY}

Tropical cyclones are categorised on a scale of 1 to 5 , according to the estimated gust wind speed at $10 \mathrm{~m}$ height, in Terrain Category 2 as per AS/NZS

* Paper S06-959 submitted 6/11/06; accepted for publication after review and revision 15/12/06.

+ Corresponding author Dr John Ginger can be contacted at john.ginger@jcu.edu.au.
1170.2 (Standards Australia, 2002) and central pressure, as shown in table 1 . Tropical Cyclone Larry formed in the Coral Sea about $1200 \mathrm{~km}$ east of Innisfail on 18 March 2006. Figure 2, courtesy of the Bureau of Meteorology, shows cyclone Larry steadily intensifying as it travelled in a westerly direction and crossing the Queensland coast about $10 \mathrm{~km}$ east-southeast of Innisfail, with a category 4 intensity at about 6.30 am on Monday 20 March 2006. The cyclone then travelled in a west-northwest track overland at a rapid forward speed of about 30 $\mathrm{km} / \mathrm{h}$ with the eye, which had a diameter of about $25 \mathrm{~km}$, passing directly over Innisfail. Strong winds were experienced more than $50 \mathrm{~km}$ inland on the Atherton Tablelands.

\section{3}

\section{WIND SPEED ESTIMATIONS FOR THE STUDY AREA}

Wind speed, direction and barometric pressure measurements obtained from the South Johnstone Automatic Weather Station (AWS) are shown in figure 3. At this site, the approach wind direction changed from $185^{\circ}(\mathrm{S})$ to $80^{\circ}(\mathrm{E})$, with corresponding peak gust wind speeds of 51 and $41 \mathrm{~m} / \mathrm{s}$, respectively, and a minimum barometric pressure of $957 \mathrm{hPa}$, as 


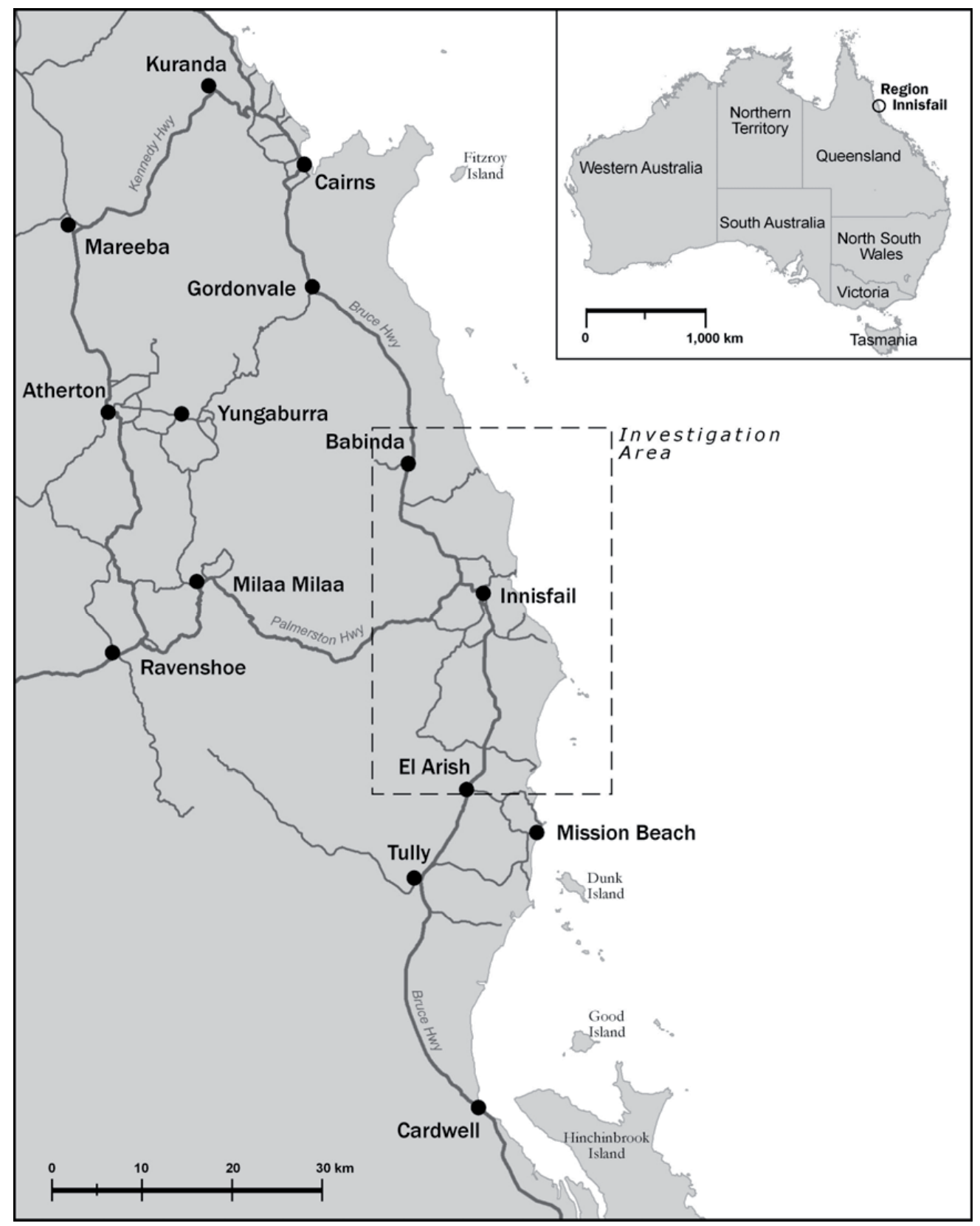

Figure 1: Locality of investigation area.

Table 1: $\quad$ Bureau of Meteorology cyclone categories.

\begin{tabular}{|c|c|c|c|c|}
\hline \multirow{2}{*}{$\begin{array}{c}\text { Cyclone } \\
\text { category }\end{array}$} & \multicolumn{2}{|c|}{ Gust wind speed at 10 m height in flat open terrain } & Central pressure \\
\cline { 2 - 5 } & $k m / h$ & $k n o t s$ & $m / s$ & $h P a$ \\
\hline 1 & $<125$ & $<68$ & $<35$ & 990 \\
\hline 2 & $125-170$ & $68-92$ & $35-47$ & $950-965$ \\
\hline 3 & $170-225$ & $92-122$ & $47-63$ & $930-945$ \\
\hline 4 & $225-280$ & $122-155$ & $63-78$ & $<925$ \\
\hline
\end{tabular}




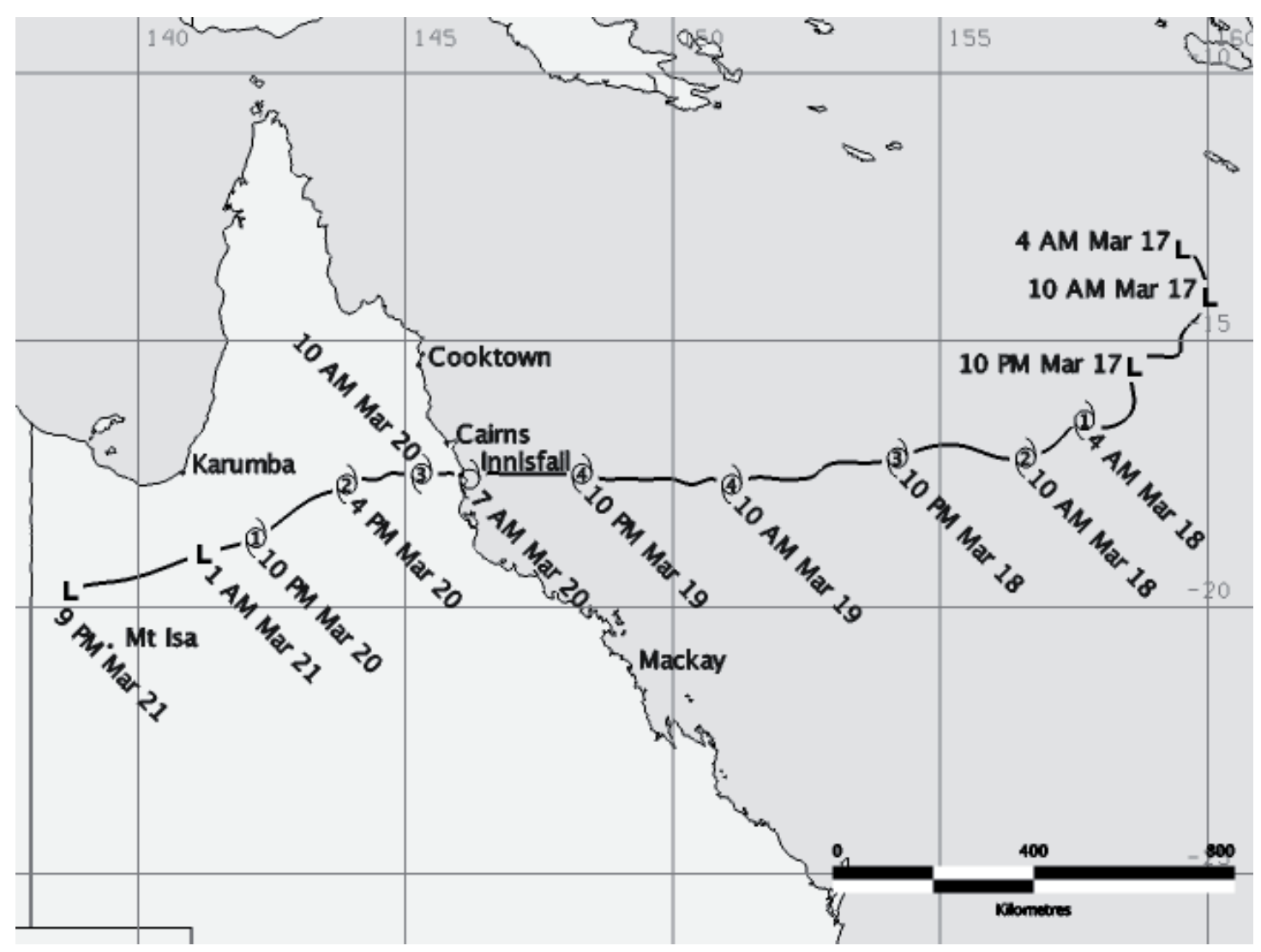

Figure 2: Tropical Cyclone Larry - estimated track (courtesy Bureau of Meteorology).

the eye passed just to the north of the site. Higher wind speeds and lower central pressures would be expected near landfall. Based on evidence from damage to structures and vegetation, and discussions with residents, the strongest winds in Innisfail were from the south to south-southeast and then from the west to northwest following the passage of the eye. In Kurrimine Beach and Mourilyan (in the areas to the south of Innisfail), the strong winds were southeast to south-southeast, and south-southwest to northnorthwest in Babinda and Mirriwinni (areas to the north of Innisfail).

\subsection{Analysis of simple structures}

Simple structures (ie. road-signs) can be used as a reliable means for estimating the peak wind speeds in the study area. These signs are generally flat plates that are attached to one or two cantilevered posts, and located in clear exposed approach terrain adjacent to the road. Basic structural analysis theory is used to determine the wind load required to bend these post(s) from which either the upper or lower bound of peak gust wind speed at its location is calculated. Upright posts give an upper bound (U) to the wind speed as the signs resisted the wind loads, while bent posts give a lower bound (L) to wind speed, as they failed during the event.

The peak net wind load, $F_{n}$, across the sign is shown in figure 4 and given by equation 1 .
$F_{n}=\frac{1}{2} \rho \hat{V}_{h}^{2} \cdot C_{F, n} \cdot A$

where $C_{F, n}$ is the net force coefficient, equivalent to $C_{f i g}$ in AS/NZS1170.2 (Standards Australia, 2002); A is the area of the plate (ie. road-sign); $\rho$ is the density of air; and $\hat{V}_{h}$ is the 3 s gust velocity at the centroid (ie. $h_{1}+0.5 h_{2}$ ) of the sign.

The resulting maximum (ie. base) bending moment, $M_{\max }$ on the post(s) is given by equation 2, where the lever-arm $l$ is the distance from the plastic hinge in the posts (ie. point of bending failure, typically close to the base) to the centroid of the sign.

$$
M_{\max }=F_{n} \cdot l=\left(\frac{1}{2} \rho \hat{V}_{h}^{2} \cdot C_{F, n} \cdot A\right) \cdot l
$$

The plastic moment capacity of the posts, $M_{p}$, is given by equation 3 , where $f_{y}$ is the yield strength of the material and $s$ is the plastic section modulus.

$$
f_{y}=M_{p} / s ; M_{p}=f_{y} \cdot s
$$

A plastic hinge in the post(s) is created when the bending moment generated by the wind load exceeds the plastic moment capacity $M_{p}$ of the post(s), as shown in equation 4 . The wind speed at centroid height required to cause failure of the post(s) is then determined from equation 5 .

$$
M_{\max } \geq M_{p} ;\left(\frac{1}{2} \rho \hat{V}_{h}^{2} \cdot C_{F, n} \cdot A\right) \cdot l \geq f_{y} s
$$




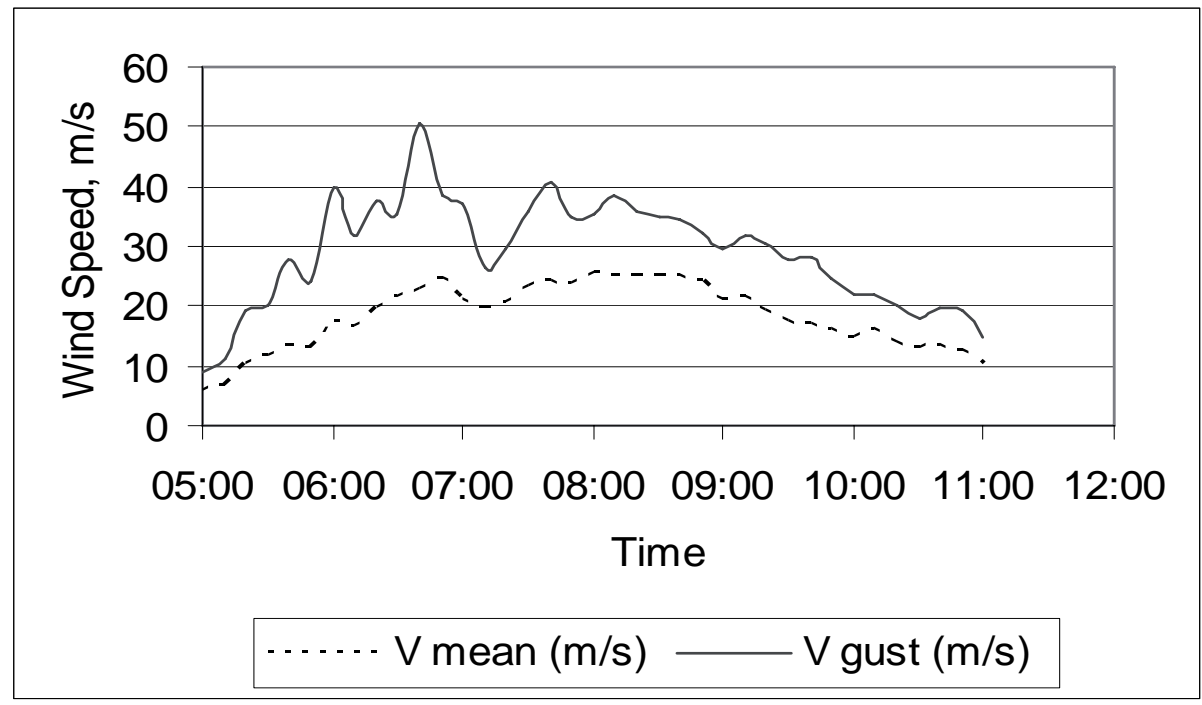

(a)

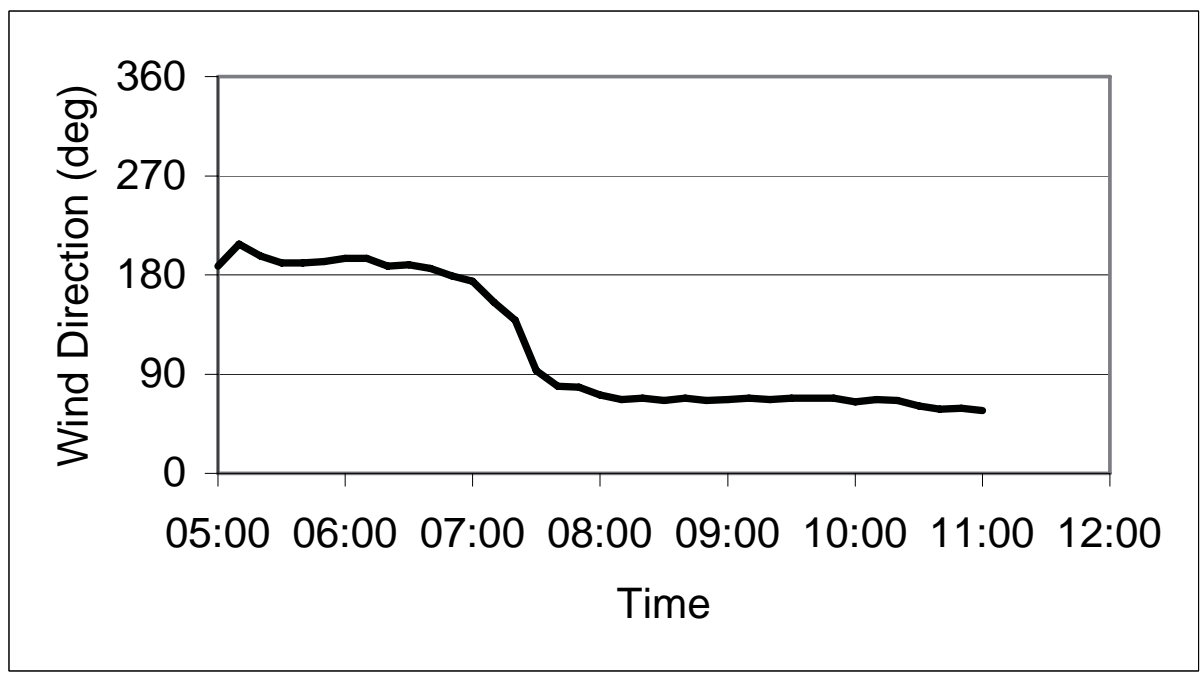

(b)

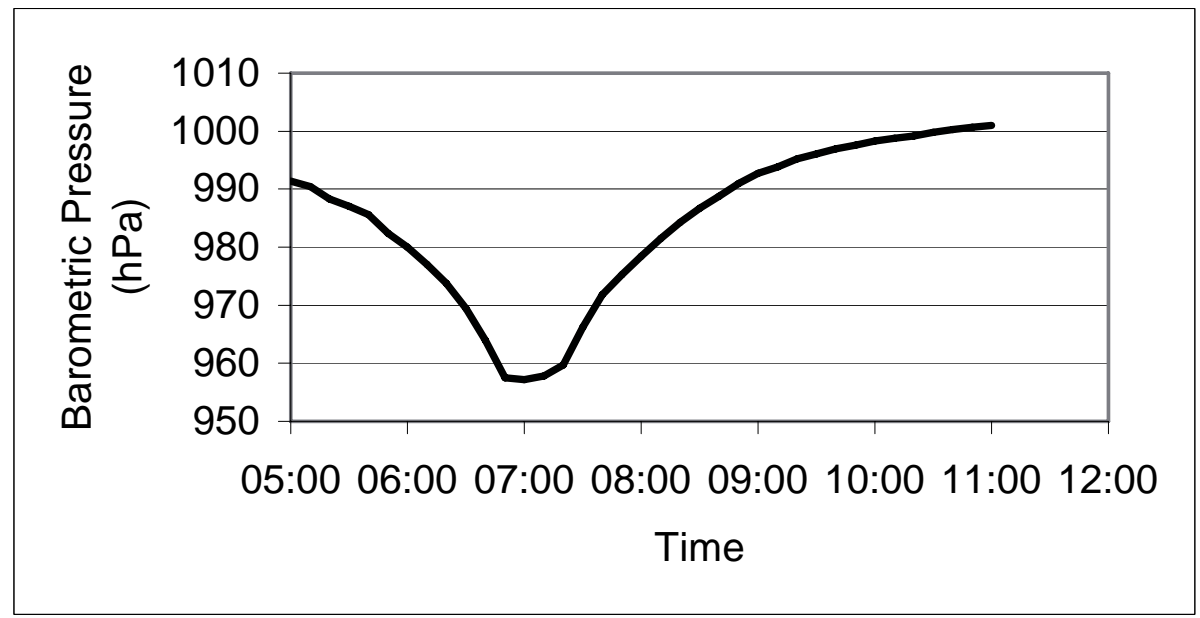

(c)

Figure 3: South Johnstone AWS data for (a) wind speed, (b) wind direction and (c) atmospheric pressure (courtesy Bureau of Meteorology). 


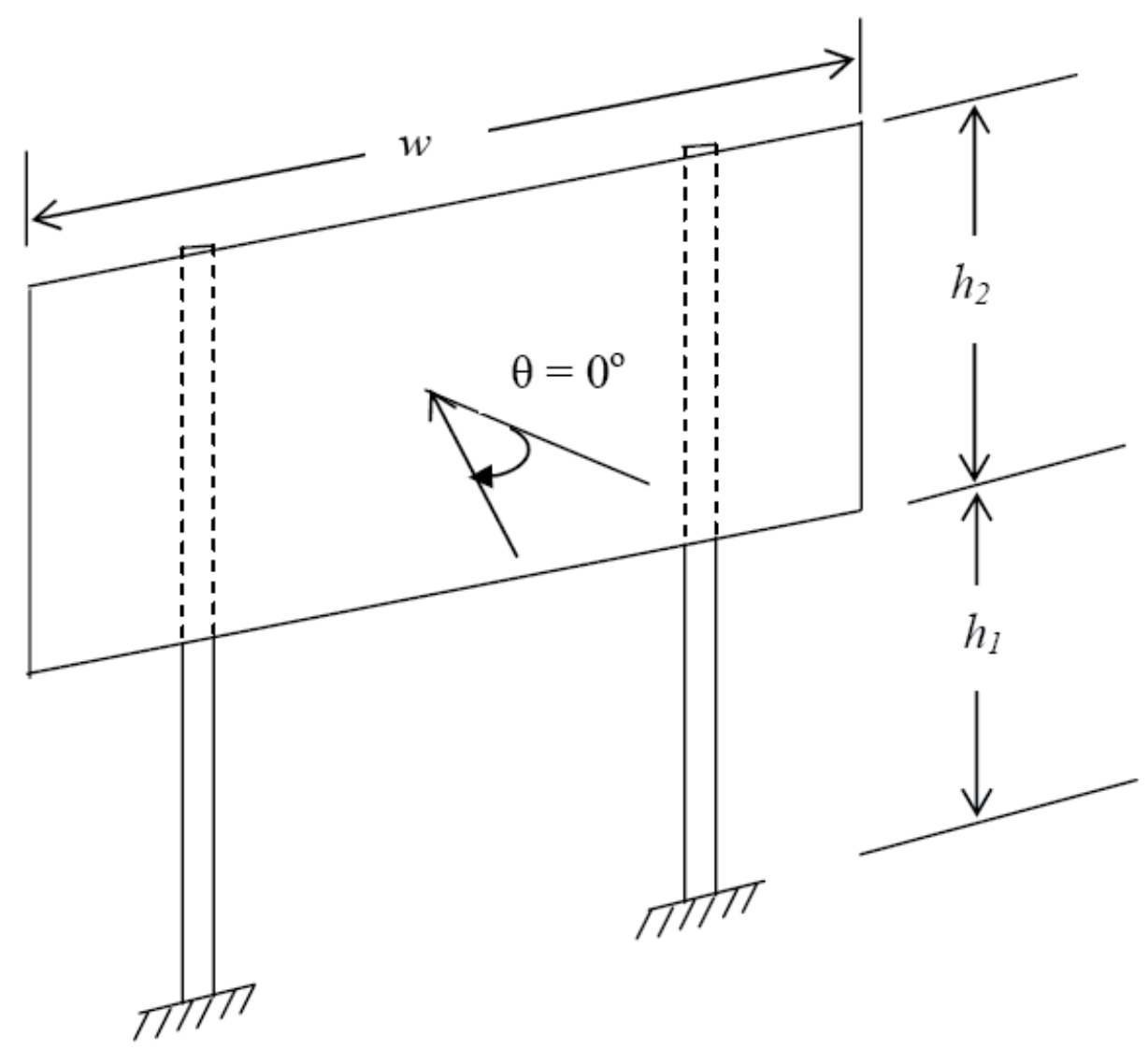

Figure 4: $\quad$ Typical road sign (Area $A=w \times h_{2}$ ).

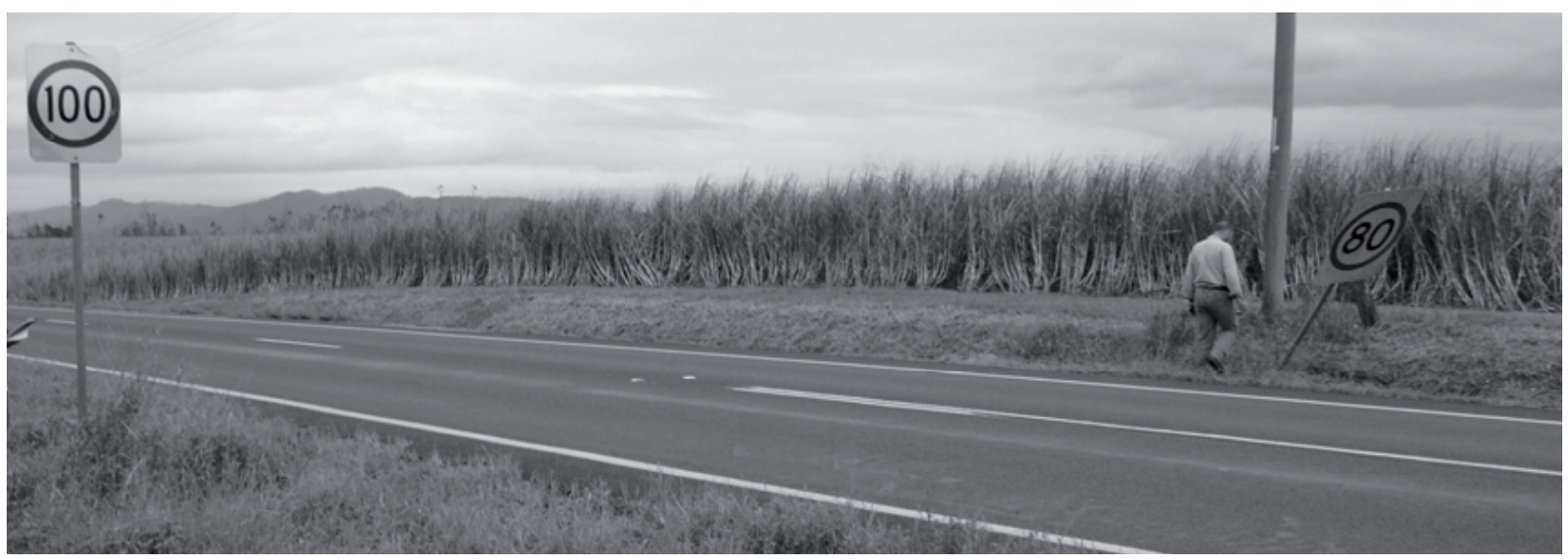

Figure 5: $\quad$ Road-signs giving Upper (ie. upright) and Lower (ie. bent) bound wind speeds (Bruce Highway, south of Innisfail).

$$
\begin{aligned}
& \hat{V}_{h}^{2} \geq f_{y} s /\left[\left(\frac{1}{2} \rho \cdot C_{F, n} \cdot A\right) \cdot l\right] \\
& \hat{V}_{h} \geq \sqrt{f_{y} s /\left[\left(\frac{1}{2} \rho \cdot C_{F, n} \cdot A\right) \cdot l\right]}
\end{aligned} ;
$$

This wind speed is then factored by accounting for the approach terrain and topography to obtain the post failure wind speed in Terrain Category 2 at 10 $\mathrm{m}$ height, $V_{r}$.

Importantly, Hoerner (1965) and many others have shown that for plates of these typical dimensions, $C_{F, n}$ is almost constant for winds approaching within $\theta= \pm$ $45^{\circ}$ from normal to the face, as shown in figure 4 . This means that these road signs can be used as a robust indicator of wind speeds for winds approaching from two $90^{\circ}$ sectors on opposite sides of the compass.

The estimated values of $V_{r}$ are dependent on the dimensions of the sign and posts, the strength of the post material, and the values of $C_{F, n}$ and terrain roughness. Sample specimens of these posts were subjected to third-point bending tests at the CTS to determine their plastic moment capacities $M_{p}$. Figure 5 shows a bent-over larger signage area road sign and an upright smaller signage area road sign located on either side of the Bruce Highway, just south of Innisfail. The corresponding $10 \mathrm{~m}$ Terrain Category 2 wind speeds required to create the plastic hinges are 


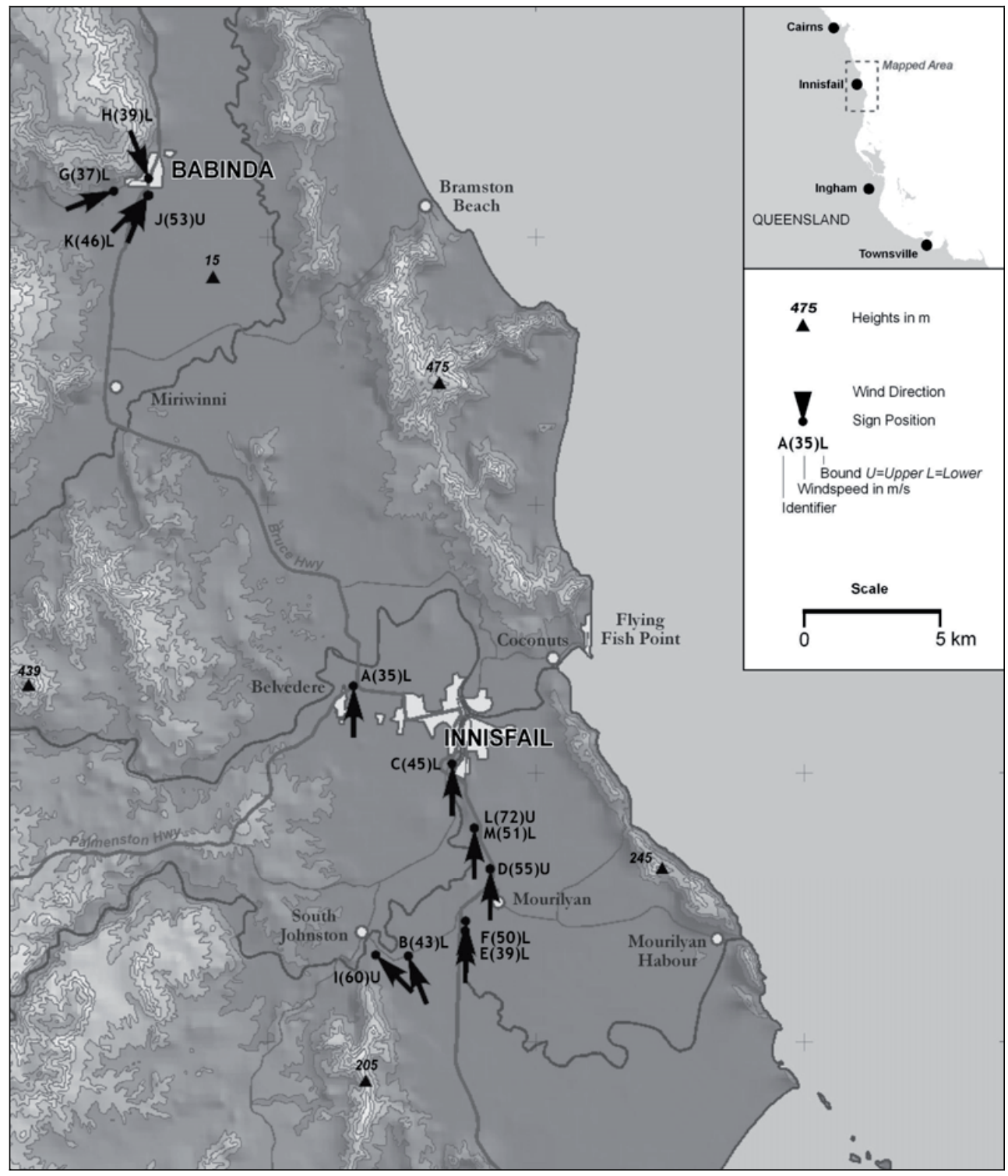

Figure 6: $\quad$ Upper and Lower bound wind speeds based on analysis of road-signs.

51 and $72 \mathrm{~m} / \mathrm{s}$, respectively, giving a lower bound (L) from the larger sign and an upper bound (U) from the smaller sign, indicating that the maximum gust wind speed was between these two values in this area. Similar analyses were conducted on a number of signs in the study area, and the $\mathrm{U}$ and $\mathrm{L}$ wind speeds obtained are indicated on the map in figure 6 . Based on this and other damage, the maximum (10 $\mathrm{m}$ reference height, in flat open terrain) gust wind speeds in the study area are estimated at between 50 and $65 \mathrm{~m} / \mathrm{s}$. Local wind speeds can, however, be greatly affected by topographic features such as hills, escarpments and valleys.

Category 3, Tropical Cyclone Winifred crossed the same area of the North Queensland coast in February 1986. Maximum gust wind speeds between 50 and $55 \mathrm{~m} / \mathrm{s}$ at $10 \mathrm{~m}$ height in Terrain Category 2 were experienced in the most severely affected areas. Investigations of the damage to buildings by Reardon et al (1986) indicated that houses built to the provisions of the Queensland Home Building
Code (1981) generally performed well. Structural damage to newer homes was mainly attributed to the effects of topography on wind speeds. The most common failure in older houses that predated these cyclone resistant building requirements was loss of roof cladding, often with battens attached.

\section{WIND LOADING DESIGN CONSIDERATIONS}

The Building Code of Australia (BCA), published by the Australian Building Codes Board (ABCB) (1996), stipulates design criteria for the majority of buildings in Australia. These requirements are met by compliance with a range of Standards relating to building design and construction (eg. AS/NZS1170.2 (Standards Australia, 2002) and AS4055 (Standards Australia, 2006)).

Houses in Townsville and Darwin suffered significant damage during Cyclone Althea and Cyclone Tracy, 
respectively, in the 1970s. This resulted in the Home Building Code of Queensland (1981) being included as Appendix 4 to Standard Building by-laws, which was in widespread use by the mid 1980s. Other related standards, such as wind loads for housing AS4055 (Standards Australia, 2006) and residential timber framed construction for cyclonic regions AS1684.3 (Standards Australia, 2005), are used in more recent housing design and construction.

Innisfail is located in Cyclone Region C, as defined in AS/NZS1170.2 (Standards Australia, 200s), where the ultimate limit state design wind speed (in flat approach Terrain Category 2) $V_{R}$ is $69 \mathrm{~m} / \mathrm{s}$. The design wind speed at the roof height of the building $V_{h}$ is calculated by using factors to account for wind directionality $M_{d}$, terrain and height $M_{z, \text { cat }}$ shielding $M_{s}$, and topography $M_{t}$, as shown in equation 6 . The design pressures on structural components are calculated using equation 7 , where $\rho$ is the density of air; $C_{f i g}$ is the aerodynamic shape factor (obtained using external and internal pressure coefficients and relevant factors given in AS/NZS1170.2 (Standards Australia, 2002)); and $C_{d y n}=1.0$ for the buildings considered in this paper. Accordingly, the wind load acting on a component of a building is proportional to square of the wind velocity. Hence, a 10\% increase in wind speed results in a $21 \%$ increase in wind load on the component.

$$
\begin{gathered}
V_{h}=V_{R} M_{d}\left(M_{z, c a t} M_{s} M_{t}\right) \\
p_{\text {design }}=0.5 \rho V_{h}^{2} C_{\text {fig }} C_{d y n}
\end{gathered}
$$

AS4055 (Standards Australia, 2006) provides design wind speeds and wind loads (which are based on AS/NZS 1170.2) for the design of typical domestic housing. A wind classification is given depending on the wind region (ie. non-cyclonic or cyclonic) and terrain, topography, and shielding at the site. In cyclonic region C, classifications $\mathrm{C} 1, \mathrm{C} 2, \mathrm{C} 3$ and $\mathrm{C} 4$ represent increasing design wind speed 50, 61, 74 and $86 \mathrm{~m} / \mathrm{s}$, respectively, at mid-roof height of $6.5 \mathrm{~m}$, based on the effects of topography, terrain category and shielding. In addition, full internal pressurisation is implicit for ultimate strength limit state design of houses in cyclone regions. An under-classification of a site (ie. C2 house built on a C4 site) can therefore result in significantly inadequate design details in the house. Furthermore, sites located on very steep hills (ie. slope greater than 1:3) and open approach terrain (ie. ocean) are not classified in AS4055, and hence houses on such sites must be designed according to AS/NZS1170.2.

For timber framed housing, the construction methods specified in AS1684.3 are based on the design wind load data given in AS/NZS1170.2 and AS4055. For each classification C1 to C4, AS1684.3 gives design (uplift) wind load on roof battens and roof framing for some typical batten and frame spacings. In addition, AS1684.3 also gives uplift capacities for typical batten-truss/rafter connections, rafter-rafter connections and truss/rafter-top plate connections (ie. nails, screws, framing anchors, straps, etc). Standards on windows in buildings AS2047 (Standards Australia, 1999a) and domestic garage doors AS/NZS 4505 (Standards Australia, 1998) use the design wind speeds and classifications given in AS/NZS1170.2 and AS4055 to specify design requirements for windows and roller-doors, respectively.

\section{BUILDING STOCK IN STUDY AREA}

The building stock analysed in the Innisfail area is categorised as Housing, Other types being Public (ie. schools, shire halls, church halls, etc.), Commercial and Industrial buildings.

\section{$5.1 \quad$ Housing}

The performance of housing was assessed by conducting a walk-by street survey. The house types defined as pre- and post-1985 (related to the application of the design and construction standards in about 1985) in this paper were recorded in the survey along with the visible damage sustained. In some cases, older houses have been renovated using newer design and construction practices, and also using different materials. Often windows were replaced and in some cases plasterboard was laid over fibro or hardboard internal linings. In some cases, renovation included some structural changes. Descriptions of house types including their structural forms are detailed in the report by Henderson et al (2006).

\subsubsection{Performance of housing}

The damage classification system used in the street survey is based on that developed by Leicester \& Reardon (1976) for Darwin after Cyclone Tracy, and listed in table 2. It ranks the amount of visible structural damage, with the categories ranging from negligible or non-structural damage, such as loss of guttering or flashing to "severe" (the latter being loss of all walls and roof structure). This survey is aimed at obtaining a representative sample of houses in the affected areas and to give an indication of the degree of damage to each house type.

The damage categories relate only to structural damage visible from outside the buildings. The lack of dense gardens or fences typically allowed the observation of the two side-walls and front-facing wall. It is likely that some lower level damage, such as debris impact or even damaged roofing, may have been missed. Furthermore, the survey does not identify damage to the interior of buildings and 


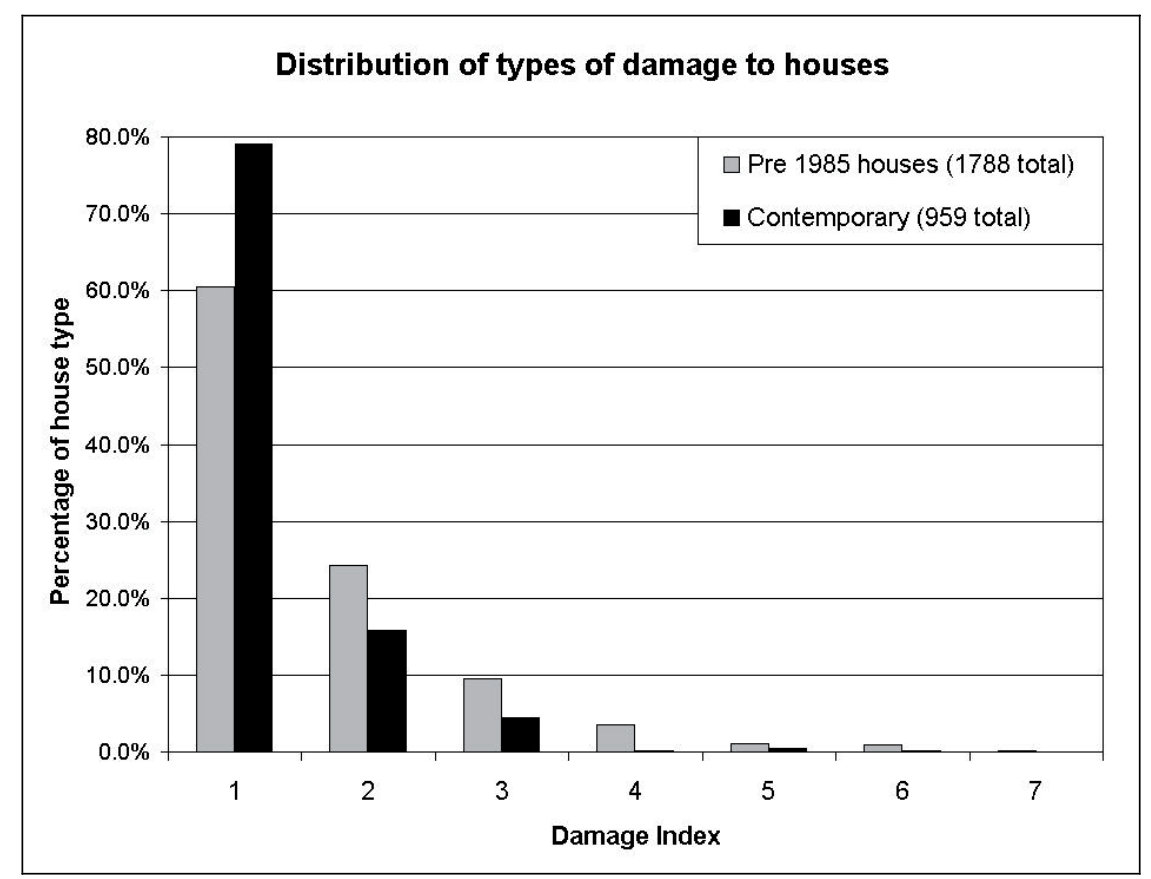

Figure 7: $\quad$ Percentage of Houses by Damage Index (all houses sampled).
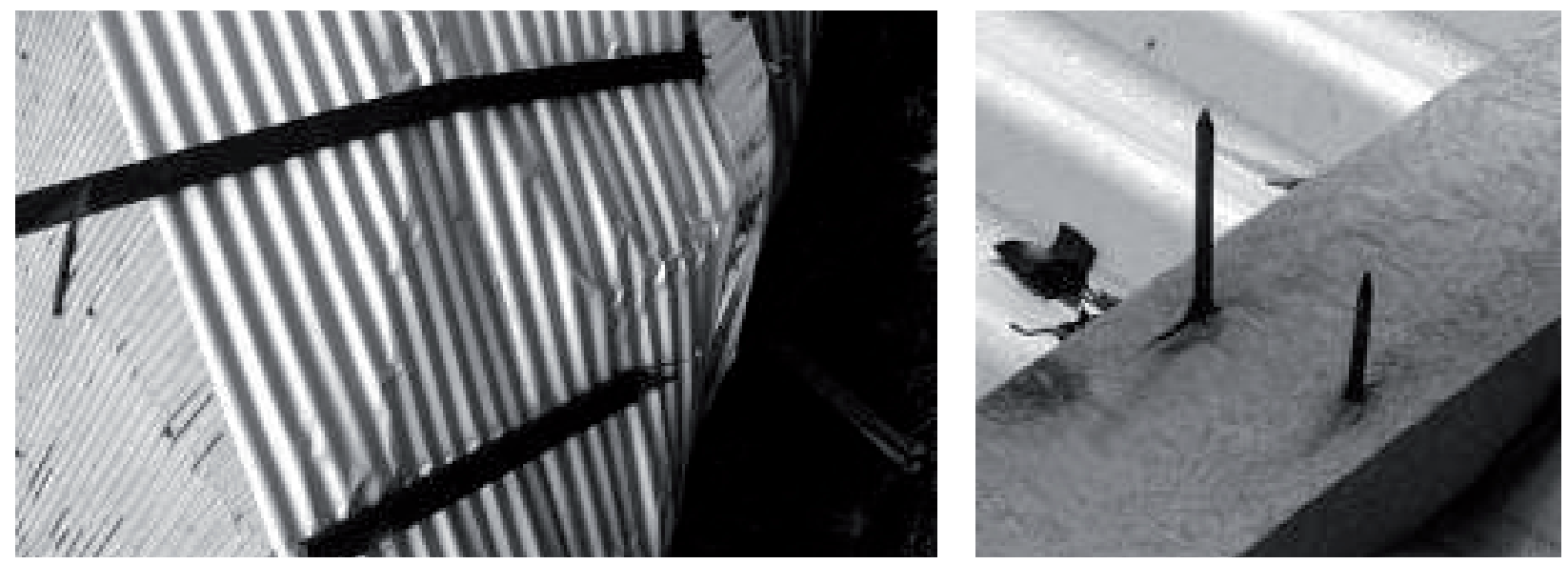

Figure 8: Failure of batten-to-rafter connection.

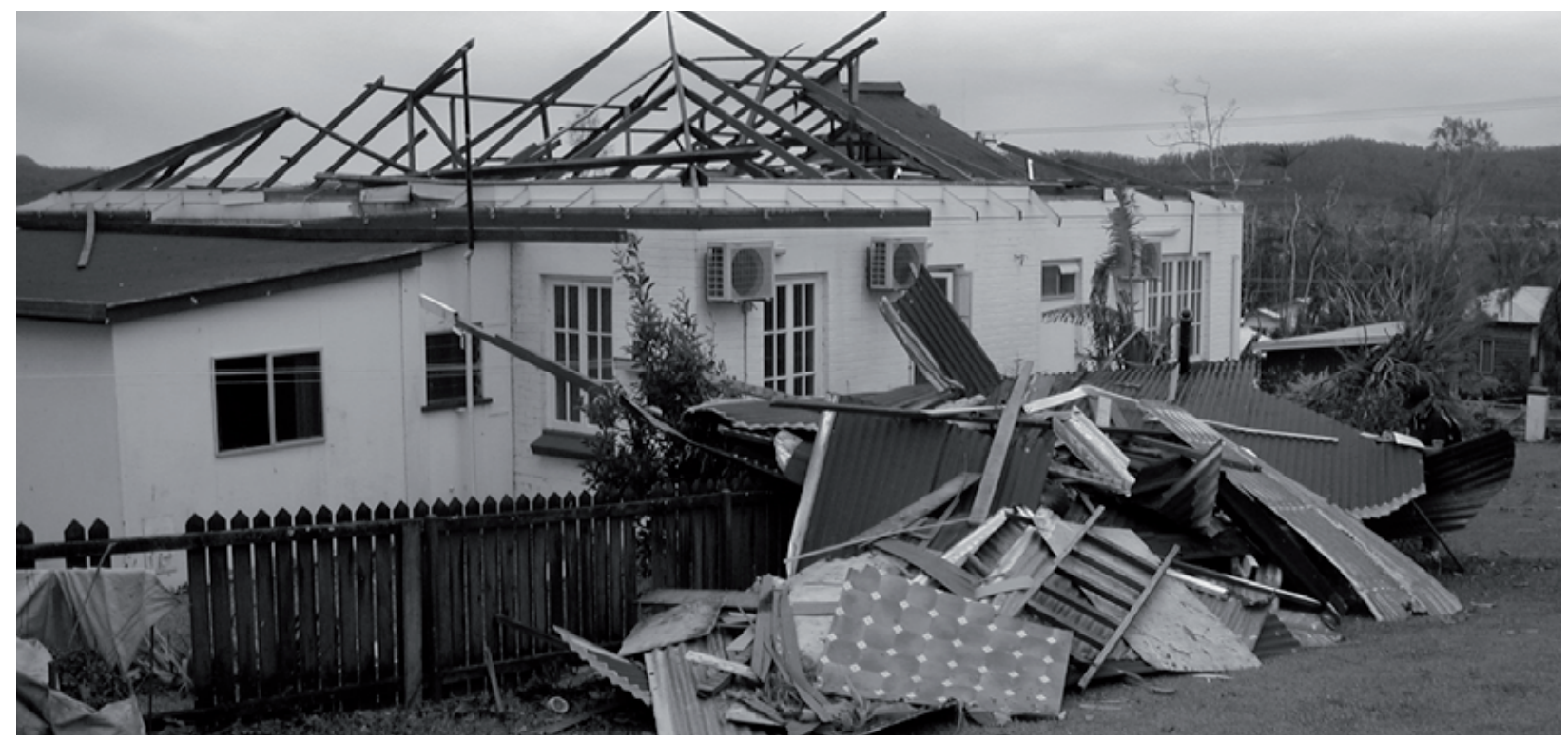

Figure 9: Loss of ridge beams. 
Table 2: $\quad$ Housing survey Damage Index.

\begin{tabular}{|c|c|}
\hline Damage Index & Description of damage \\
\hline 1 & No or Negligible damage \\
\hline 2 & Missile/debris damage to cladding, gutters or windows \\
\hline 3 & $\begin{array}{l}\text { Loss of up to half of roof sheeting (including battens that were often still } \\
\text { attached to the sheeting) }\end{array}$ \\
\hline 4 & $\begin{array}{l}\text { Loss of more than half of roof sheeting (including battens that were often still } \\
\text { attached to the sheeting) }\end{array}$ \\
\hline 5 & $\begin{array}{l}\text { Loss of roof structure (includes loss of sheeting, battens, rafters, struts, } \\
\text { and top plates) }\end{array}$ \\
\hline 6 & Loss of up to half of walls \\
\hline 7 & Loss of more than half of walls \\
\hline
\end{tabular}

contents from water ingress, for example. If a house sustains more than one damage category, then it is assigned the most severe damage index.

This paper presents data from a sample of 2747 houses, of which approximately $50 \%$ were sampled by teams from GeoScience Australia using the same CTS damage classifications. The results are presented as Percent of housing damaged vs Damage Index (DI) in figure 7. Figure 7 shows that, overall, contemporary housing (1985+) had a much higher percentage of negligible damage (DI-1) than the pre-1985 houses. There was also a smaller percentage of contemporary housing that suffered significant structural damage (ie. DI-3 to DI-8), compared to older houses. Overall, about $20 \%$ of housing experienced significant structural damage (ie. DI-3 to DI-8).

\subsubsection{Pre-1985 houses}

The houses in this category that pre-dated the revision of the Queensland Building By-Laws - Appendix 4 (Queensland Home Building Code, 1981) had the largest variation in performance, reflecting the range of house types, age and structural quality in the building stock. Some houses had been structurally renovated, and others had been refurbished with linings and roofing, but suffered structural deterioration. There were a number of examples where failures could be attributed to corroded fasteners or deteriorated timber components. Failures were also attributed to the connections not having the capacity to resist the wind loads, even without deterioration.

The most common type of failures in housing of this era was at the batten-to-rafter connection, as illustrated in figure 8 . In a number of cases, the roofing had been replaced, and stronger Type 17 roofing screws replacing the spring-head nails used during the original construction. However, the original batten-rafter connections, which typically had two $75 \mathrm{~mm}$ nails or in some cases one nail per connection, were generally not upgraded to the required strength. The next point of weakness along the hold-down chain was at the rafter-to-wall connection, where the roof is anchored to the top of walls with skew nails, a potential failure mode if the cladding and battens stay attached to the rafter.

Another type of failure was the loss of the central part of the roof as shown in figure 9. Generally, these roofs were anchored with over-battens around the edge and relied on ridge beams and underpurlins for support of the rafters at the top and centre of each rafter run. When these support points did not offer enough anchorage against the wind uplift forces, they failed, sometimes leaving the outside connection of the rafters still attached to the wall, but the centre part of the roof missing.

Figure 10 shows a house in which batten-to-rafter connections were upgraded with straps at the same time that the roofing was replaced. This roof section remained intact, but extensive damage to the windward wall and roof edge combined with water ingress caused the ceiling collapse that enabled this photograph to be taken. Batten to rafter connection failures were rare in houses that had been fitted with batten-to-rafter straps, although there were a number of cases of loss of the roof structure due to failure of the connection at top plate level.

During subsequent detailed inspections, "hidden" failures, such as partially pulled out nails leaving a separation between the battens and rafters in the pre1985 homes, were found. A few cases of separation of top plate and studs were also noted. In such cases, the wind load was sufficient to overload some of the 
nailed joints, but the subsequent wind gusts (and short cyclone duration) were not able to completely pull-out the nails. Batten-to-rafter connection specifications are given in AS1684.3 (Standards Australia, 2005), with design data allowing the calculation of uplift force on a connection and the capacity of a number of different connection types. Two deformed shank nails do not have sufficient capacity for edge zones in a metal deck roof, and plain shank nails are not listed as options for use in cyclone regions.

When the roof is lost, collapse of walls occur due to loss of support from the ceiling and roof structure, in some cases aggravated by deterioration of the structure at floor level. There were only one or two examples in which it was thought that the wall had failed prior to the roof loss due to deterioration of the structure.

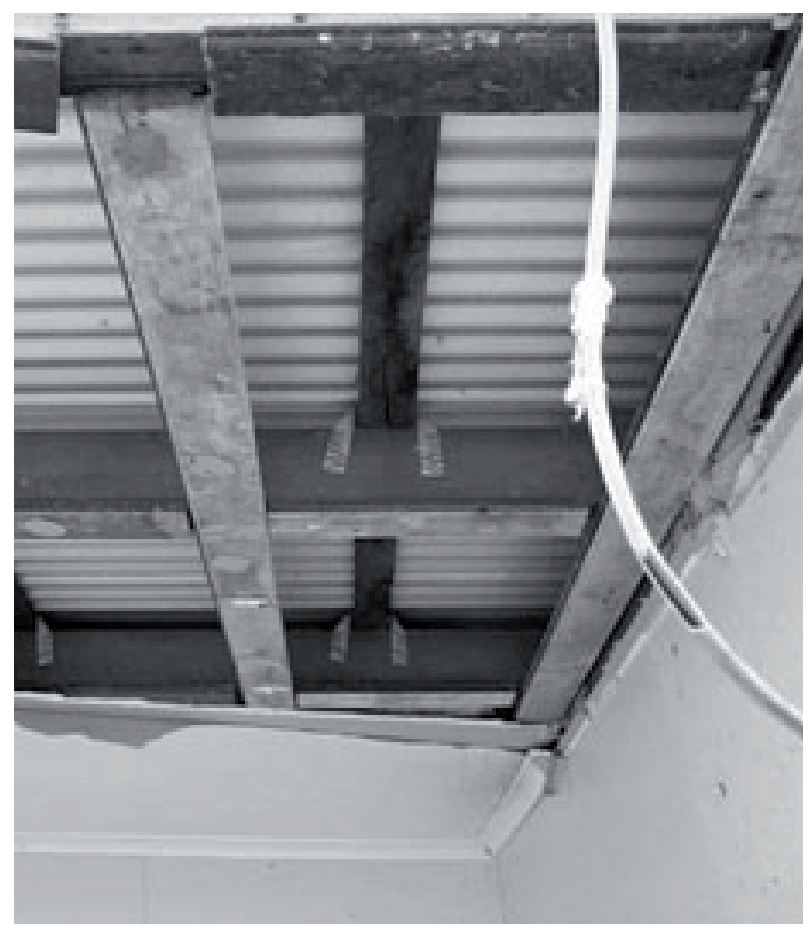

Figure 10: Improvements in batten-to-rafter connection.

\subsubsection{Post-1985 (contemporary) housing}

Most of the contemporary houses in the study area were slab-on-ground houses. The majority of these had hollow masonry block walls. Figure 7 shows that contemporary housing suffered less structural damage than pre-1985 housing. Damage to contemporary housing could mainly be traced to either debris impact, or to inadequate fastening of windows, roller-doors, tiles, facias and guttering. There were examples of wind driven debris penetrating both metal deck roofs and tile roofs causing damage, as shown in figure 11.

The more significant damage was generally associated failure of connections, where unsatisfactory detailing of joints resulted from incorrect AS4055 site classification (ie. building a C2 house on a C4 site). Two contemporary elevated houses had structural damage attributed to their hill-top locations experiencing higher wind speeds than the structural detailing catered for. Many other contemporary elevated houses that were subjected to higher wind speeds due to topography had minimal damage.

\subsection{Non-domestic (ie. other) buildings}

These buildings can be categorised by their structural system and construction methods and materials used. The "older" public, commercial and industrial buildings were generally timber framed construction similar to the housing of the same era, and consequently they performed similarly. Many of the contemporary public, commercial and industrial buildings were generally open plan, steel framed, metal clad buildings. In most cases, the roofs were generally gable ended and low pitch $\left(<10^{\circ}\right)$, with roof and wall cladding attached to purlins and girts respectively, spanning across the frames. Large roller or hinged doors and glass windows or louvres were installed in these buildings.

Two groups of contemporary buildings are considered in this paper, based broadly on the type of steel section used for the main framing members. One group, using the more traditional hot-rolled steel

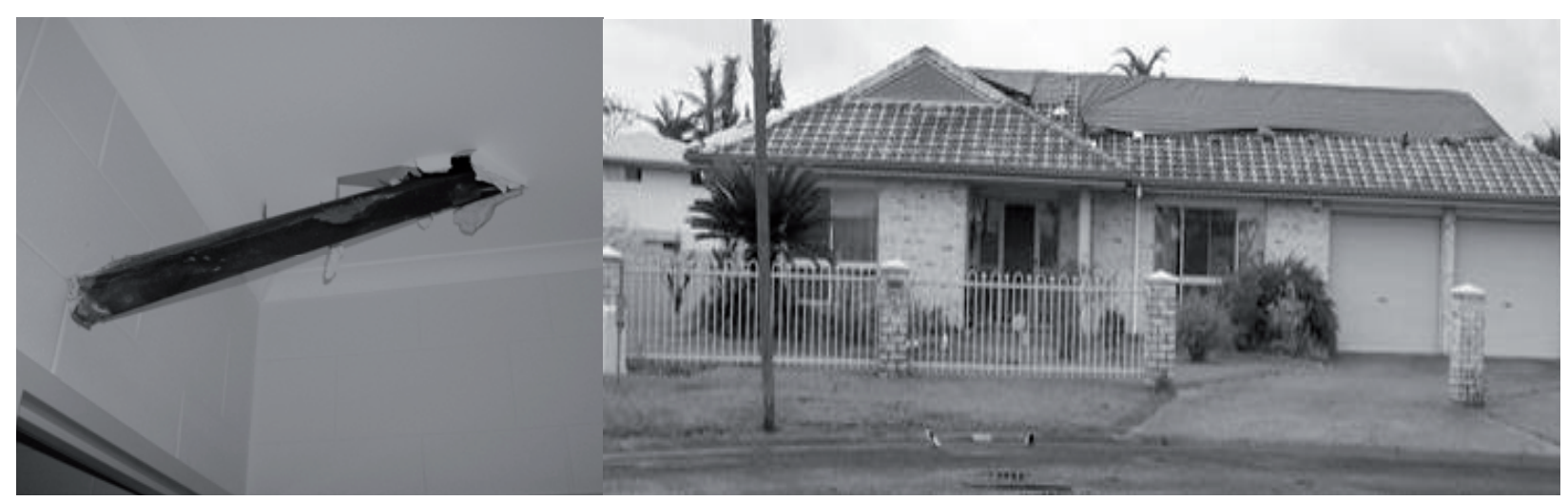

Figure 11: Debris damage to contemporary housing - (left) debris penetration through metal roof; (right) tile damage after debris impact. 


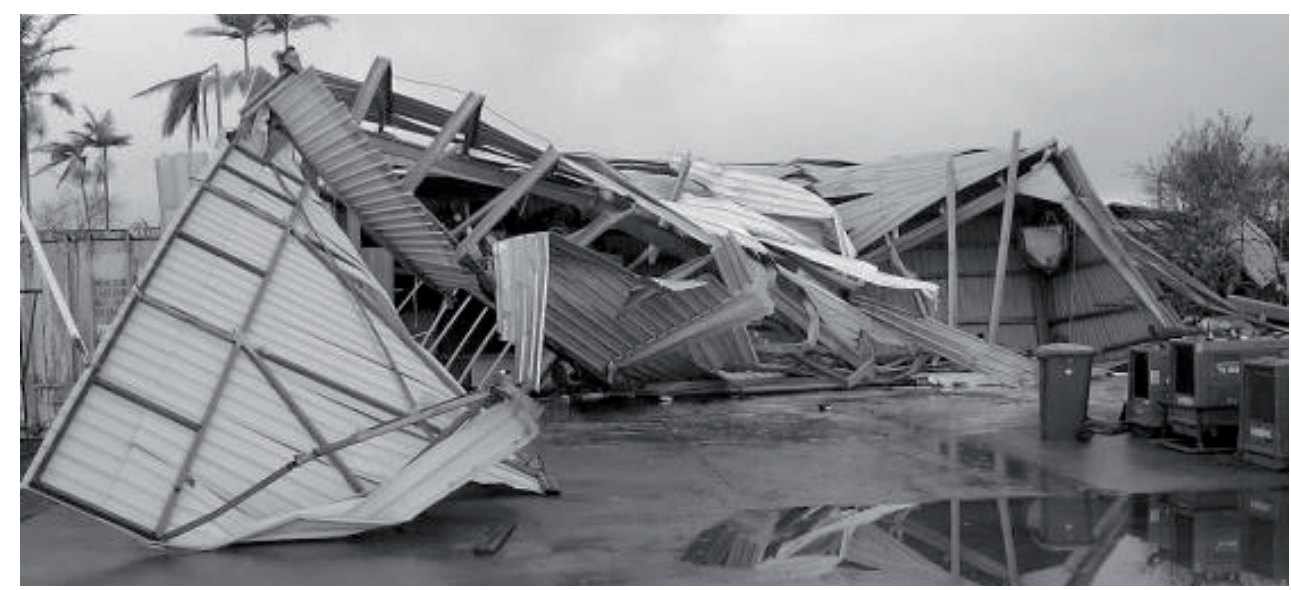

Figure 12: Collapse of cold-formed steel industrial shed.

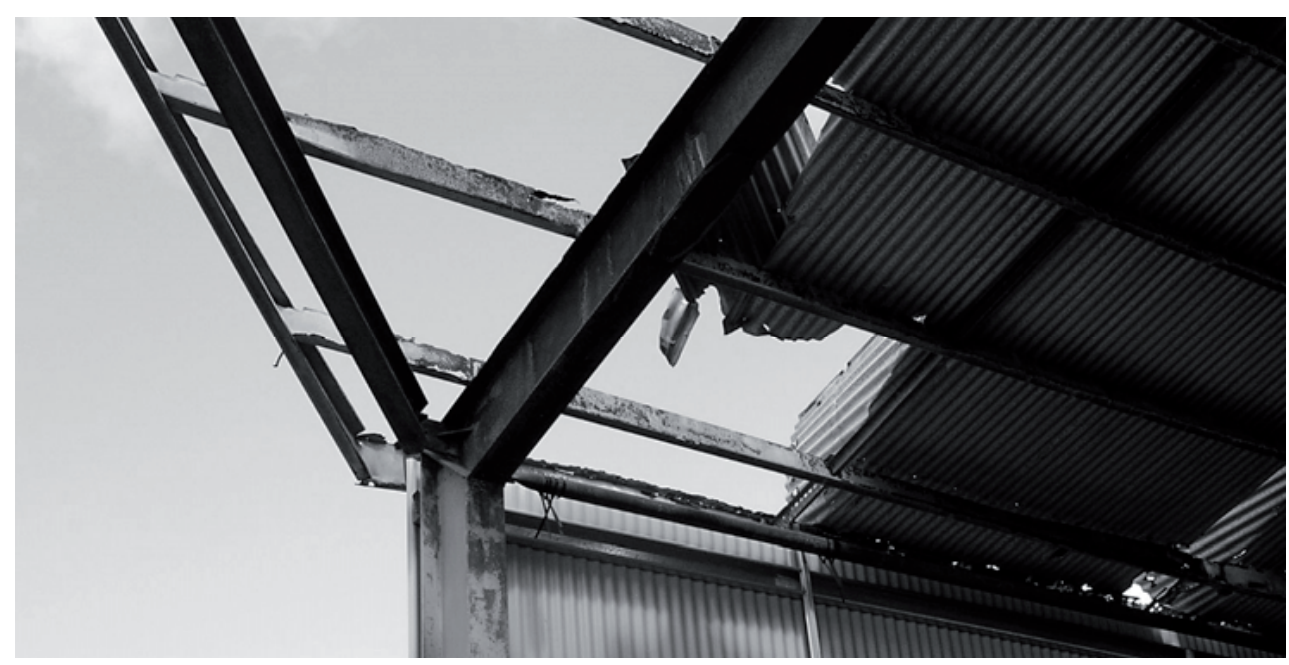

Figure 13: Hot rolled steel framed shed with severe corrosion of purlin.

Table 3: $\quad$ Typical details for the two defined types of steel framed buildings.

\begin{tabular}{|c|c|c|}
\hline \multirow{2}{*}{ Item } & \multicolumn{2}{|c|}{ Typical details for each building classification } \\
\hline & Hot Rolled Buildings & Cold Formed Sheds \\
\hline Structural framing & $\begin{array}{l}\text { Hot-rolled steel sections (UB, UC or } \\
\text { RHS members). }\end{array}$ & $\begin{array}{l}\text { Light-gauge cold formed sections } \\
\text { (C or Z members). }\end{array}$ \\
\hline $\begin{array}{l}\text { Frame connections } \\
\text { (column-to-rafter, } \\
\text { ridge joint) }\end{array}$ & $\begin{array}{l}\text { Welded connections or bolted } \\
\text { connections using thick steel plates } \\
\text { (typically } 10 \mathrm{~mm} \text { thick). }\end{array}$ & $\begin{array}{l}\text { Bolted connections, often using } \\
\text { folded light gauge brackets (typically } \\
\text { about } 2 \mathrm{~mm} \text { thick). }\end{array}$ \\
\hline Purlins and girts & $\begin{array}{l}\text { Continuous lapped } \mathrm{Z} \text { sections, fixed } \\
\text { to the frames using bolts through the } \\
\text { web of the section. }\end{array}$ & $\begin{array}{l}\text { Three methods used: continuous } Z \\
\text { sections; simple span C sections; and } \\
\text { top hat sections. Purlins and girts } \\
\text { often fixed to the frames through the } \\
\text { purlin/girt flanges. }\end{array}$ \\
\hline Bracing & $\begin{array}{l}\text { Typically SHS or CHS struts with } \\
\text { crossed tension bracing. }\end{array}$ & $\begin{array}{l}\text { Crossed tension bracing using light } \\
\text { gauge straps. Often rely on end bay } \\
\text { purlins acting as struts to support the } \\
\text { top ends of wind columns (end wall } \\
\text { mullions). }\end{array}$ \\
\hline
\end{tabular}


framing members, are called "Hot Rolled Buildings". The second group comprises the lighter (ie. less mass of steel) sheds that use light gauge cold formed steel sections (typically "C" sections) for the main structural framing elements and are called "Cold Formed Sheds" in this paper. Table 3 summarises these two groups of buildings. These buildings in Cyclone Region $\mathrm{C}$ are designed to wind speed specifications in the wind load standard AS/NZS 1170.2 (Standards Australia, 2002). However, the design internal pressure used is dependent on the designer's assessment of the occurrence of a dominant opening.

\subsubsection{Performance of steel-framed buildings}

Walk-by street surveys and detailed inspections of these buildings were conducted. Detailed findings from these inspections are presented in the report by Henderson et al (2006). A summary of the typical performance of these buildings and their components is given in this paper.

Approximately $30 \%$ of these "engineered" buildings suffered damage ranging from loss of cladding through to complete collapse. Of the buildings that had roller doors, $60 \%$ had failed doors, often causing additional internal damage and, in some cases, leading to structural failures. These failures took place at wind speeds significantly lower than the design value, where structural failures are not expected. The major structural failures were all in the cold formed steel frame sheds (figure 12). The hotrolled buildings performed better, notwithstanding the failure of the roller doors, or failures due to corrosion of elements, as shown in figure 13.

\subsection{Performance of roller doors}

A large proportion of roller doors failed in both housing and other buildings. In housing, most of the roller doors failed by disengaging from the tracks. Failures of panel lift doors in housing were also observed. In some cases, the internal pressurisation of the building as a result of a roller door failure caused further damage to the building. In general, roller doors in all types of buildings performed poorly.

\subsubsection{Roller doors in public, commercial and industrial buildings}

Most of the roller doors fitted to the larger commercial and industrial buildings had a similar pattern of damage, with the roller doors becoming disengaged from the tracks or the tracks disengaging from the walls. In some cases failure of a roller door(s) on the windward wall was quickly followed by the failure of roller door(s) on leeward and side wall(s) as a result of internal pressurisation.
The ratio of the depth of the roller door slats or ribs to the span across the door opening is very small, and so they are very flexible. Consequently, a moderate wind pressure (either inwards or outwards) causes large deflections in the mid-span region of the rollerdoor causing the ends of the slats or panel to be pulled inwards, followed by the roller door failure when the sides become disengaged from the tracks (figure 14).

Roller doors can be designed with hooks fitted to the ends of the slats (wind locks) so that when the slats are subjected to wind loading they can use membrane action to support this pressure. However, the tensile forces generated in the slats by this membrane action can be quite large (especially if the deflection at the centre of the slat span is small) and so the tracks to each side of the slats need to be fixed very securely. Typical failures associated with wind locks are shown in figure 15.

\section{OTHER ISSUES FOR BUILDINGS}

\subsection{Mechanical services}

There were many instances where airconditioning units and large ventilators had dislodged and become missiles that rolled or bounced along the roof causing impact damage during Cyclone Larry. This type of damage was observed in the business district and was caused by the failure of mountings or connections to the structure of these mechanical units. In some cases, this problem was exacerbated by corrosion of connections. Domestic ventilators also failed, allowing water ingress and contributing to debris damage.

\subsection{Deterioration and corrosion}

Deterioration and corrosion of components and connections in houses and other buildings contributed to failures, especially in the older buildings. This reinforces the need for correct material specification, and ongoing inspection and maintenance of the building stock.

\subsection{Shadecloth}

Failures of both tension-membrane shadecloth and draped shadecloth structures were observed in some carparks, nurseries, entertainment areas and farms. It appears that these structures are designed for wind speeds lower than $69 \mathrm{~m} / \mathrm{s}$, and that load reduction factors (ie. for porosity) are erroneously applied in their design. However, once the shade cloth is ripped, the risk of the cables failing at the supports is minimal. 


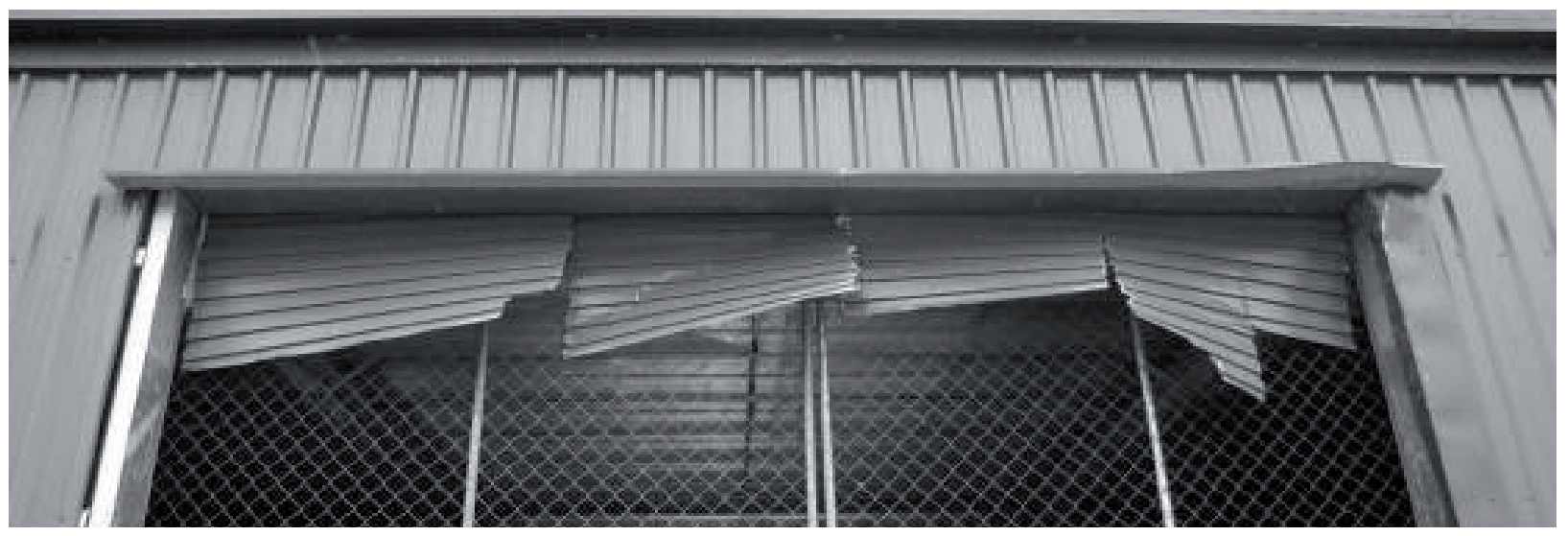

Figure 14: Torn sheet-type roller door.
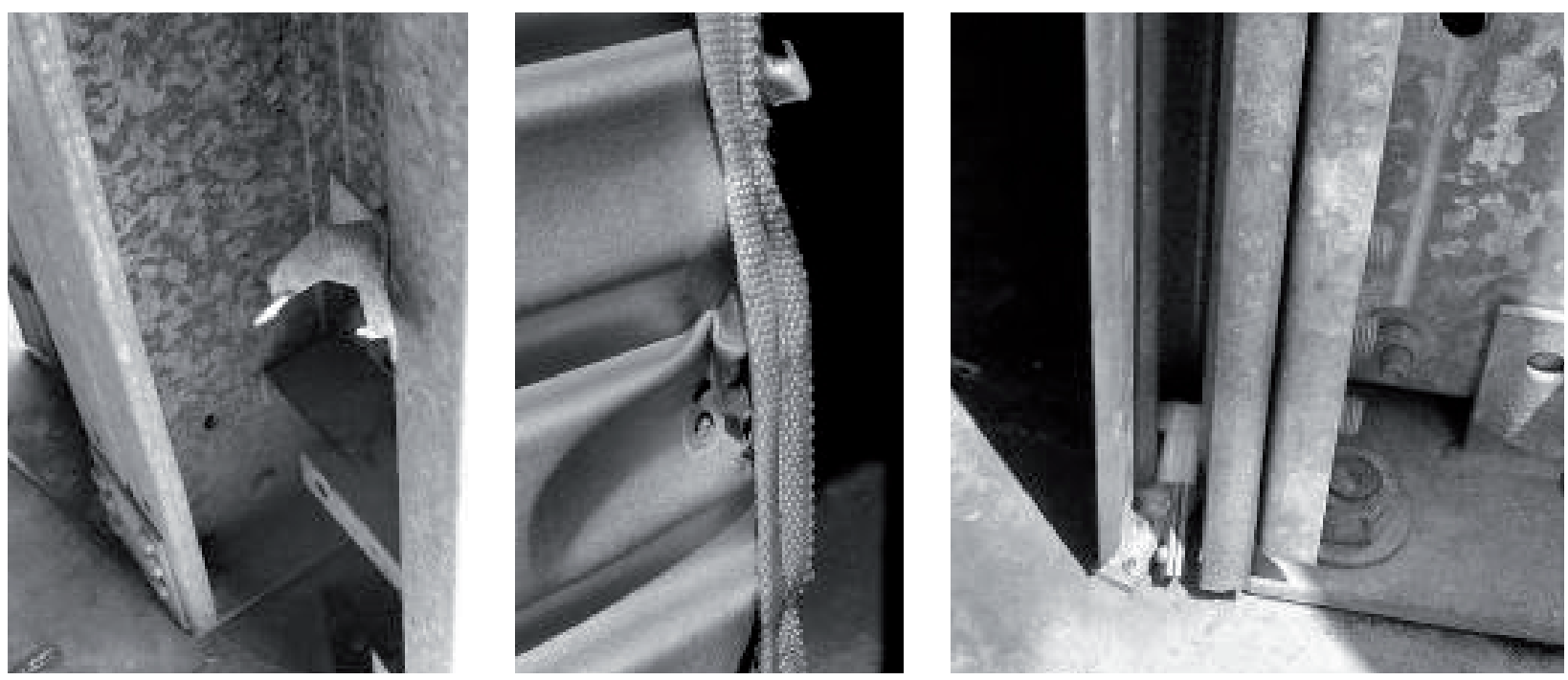

Figure 15: Failures associated with wind locks - (left) failed track bracket, (centre) wind lock torn from door and (right) wind lock in track.

\section{7}

\section{CONCLUSIONS}

Tropical Cyclone Larry caused damage to buildings in an area centred on Innisfail in North Queensland. Details of the survey and assessment of building performance are given in the report by Henderson et al (2006). This paper summarises the work presented in that report.

By assessing damage to simple structures, buildings and vegetation, the peak gust wind speed referenced to $10 \mathrm{~m}$ in open terrain and flat topography was estimated to have been in the range 50 to $65 \mathrm{~m} / \mathrm{s}$ for Innisfail and adjacent areas. These wind speeds are less than the regional design wind speed for the entire study area, so all buildings inspected were subjected to lower peak gust speeds than the design standards would have used. However, in a few areas the estimated maximum gust wind speed was approximately $90 \%$ of the regional design wind speed, so the event was approaching the design event. Tropical Cyclone Larry was a fast moving event, which meant that the duration of strong winds was relatively short. Hence, buildings experienced fewer wind pressure fluctuations and less debris impact, as well as a shorter period in which rain was being driven into buildings. Had the cyclone been moving more slowly, but with the same gust wind speeds, the debris damage, water penetration and cladding damage would have been worse.

Overall, newer buildings performed better than older building stock, with damage mainly occurring to roller doors and attachments, such as guttering and facia. This indicates that the current suite of loading, design and construction standards are effective without being overly conservative. However, even in newer buildings there was some damage that could have been avoided by strict application of the current suite of standards:

- In some cases, topographic effects had been ignored in the design and construction of newer buildings. These effects are modelled in both AS/NZS1170.2 and AS4055.

- Batten-to-rafter connections under sheet roofs of older buildings had one or two plain shank nails as the only anchorage. This is not in compliance with AS1684.3. There was no evidence of failure of batten-to-rafter 
connections that complied with AS1684.3.

- Some window and door fixings failed under wind load. In some cases, it was locks and catches, and in others it was the fixing of the frame to the structure. It is important that all components of windows and doors (including fixing to the building) be capable of resisting the design wind load.

- A significant proportion of roller doors in newer structures failed under wind loads. In many cases, wind locks had been fitted, but were ineffective due to poor anchorage of tracks to the structure or to flexibility of the doors and tracks.

- Cold formed steel framed sheds did not perform as well as other types of newer buildings. Some standard connections and elements were too light to satisfactorily handle the wind loads.

- Water penetrated most buildings with resultant damage to contents and, where linings were of plasterboard, there was ceiling or wall lining damage.

- Wind damage was more widespread among buildings that were built prior to the release of the Queensland Home Building Code Appendix 4. In many cases, these buildings had been refurbished since the 1980s, but structural details remained the same. In some cases, these buildings had been repaired following Cyclone Winifred but used the original construction details.

- Most of these deficiencies can be remedied if reconstruction is performed to current building standards, and if subsequent refurbishment is required to ensure that at least the anchorage of roof elements down as far as the top of the walls meets the current standards. Guidance for reconstruction is available from publications such as HB132.2 Structural upgrading of older houses - Part 2: Cyclone areas (Standards Australia, 1999b).

The surveys showed only very few buildings had used debris screens on doors or windows. The inspections showed a range of debris damage including:

- denting of cladding or roller doors from glancing blows from debris

- penetration of cladding under debris attack, sometimes entering the buildings

- removal of gutters fascias and other trim due to debris impact

- breakage of glass due to debris impact

- demolition of part of the building due to substantial debris impact.
In some of these cases, the debris impact load was significantly higher than the $4 \mathrm{~kg}$ mass projected at 15 $\mathrm{m} / \mathrm{s}$ specified in the test according to AS/NZS1170.2. It would therefore be appropriate for buildings in cyclone prone regions to be designed in ultimate limit state for internal pressures resulting from dominant openings, irrespective of compliance with this test.

Reconstruction should be accompanied by careful checking and supervision to ensure that all parts of the roof structure comply with current building standards. These have demonstrated their effectiveness in this near-design level event.

\section{ACKNOWLEDGEMENTS}

The authors gratefully acknowledge the support given by Australian Building Codes Board, Queensland Department of Public Works, Timber Queensland, Insurance Australia Group, Bluescope Steel, Geoscience Australia, Bureau of Meteorology, Systems Engineering Australia, JDH Consulting, Counter Disaster Rescue Services (EMQ), Emergency Management Australia, Queensland Department of Main Roads and TESAG- JCU.

The authors are also extremely grateful to the residents of the Innisfail region who generously assisted this study by volunteering information, answering questions and on occasions inviting the authors into their houses to inspect damage.

\section{REFERENCES}

Australian Building Codes Board, 1996, Building Code of Australia (BCA)96.

Henderson, D., Ginger, J., Leitch, C., Boughton, G. \& Falck, D. 2006, "Tropical Cyclone Larry - Damage to buildings in the Innisfail area", James Cook Cyclone Structural Testing Station Technical Report No. 51.

Hoerner, SF. 1965, Fluid-dynamic drag: Practical information on aerodynamic drag and hydrodynamic resistance.

Leicester, R. H. \& Reardon, G. F. 1976, “A statistical analysis of the structural damage by cyclone Tracy", Civil Engineering Transactions, Vol. CE18, No. 2, pp. 50-54, Institution of Engineers Australia.

Queensland Home Building Code, 1981, Queensland Home Building Code-Appendix 4.

Reardon, G. F., Walker, G. R. \& Jancauskas, E. D. 1986, "Effects of Cyclone Winifred on buildings", James Cook Cyclone Structural Testing Station Technical Report No. 27. 
Standards Australia, 1998, AS4505 1998 Domestic garage doors.

Standards Australia, 1999a, AS2047 1999 Windows in Buildings - Selection and installation.

Standards Australia, 1999b, HB132.2 1999 Structural upgrading of older houses - Part 2 Cyclone areas.
Standards Australia, 2002, AS/NZS 1170.22002 Structural design actions - Part 2: Wind actions.

Standards Australia, 2005. AS 1684.32005 Residential Timber-framed Construction - Part 3 Cyclonic areas.

Standards Australia, 2006, AS4055 2006 Wind loads for housing. 

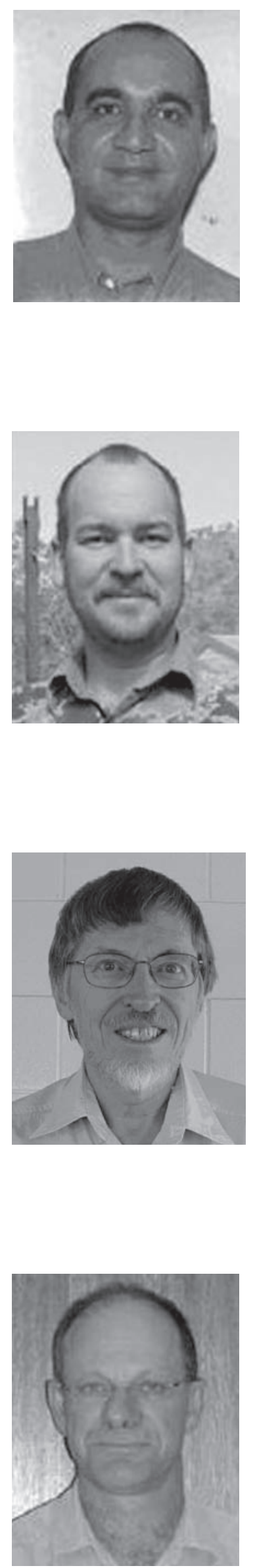

\section{JOHN GINGER}

Dr John Ginger is a senior lecturer in civil engineering and the research director of the Cyclone Testing Station at James Cook University in Townsville. He has been involved in research, testing and consulting in wind engineering since 1987. John has experience in wind tunnel model studies and full-scale field tests on projects in Australia and overseas. He is a member of Standards Australia committees on Loading on Structures and Wind Loads. He is also a member of the Queensland Tropical Cyclone Coordination committee.

\section{DAVID HENDERSON}

David Henderson has been a research engineer - breaking houses and building products, and conducting wind risk assessments - at the Cyclone Testing Station for 15 years. He has conducted cyclone and thunderstorm damage investigations across Australia. David has recently stepped down as Manager of the Cyclone Testing Station to commence PhD studies on cyclonic wind loads on roofs. He is a member of the Australian Standards Committees for Wind Loads for Housing, and the suite of design and testing standards relating to cladding systems.

\section{CAMPBELL LEITCH}

Campbell Leitch is a senior research engineer with the Cyclone Testing Station at the James Cook University in Townsville. Since 2002, he has worked as part of the Cyclone Testing Station team to perform research, testing and consulting into both the transfer and resistance of wind induced loading in low rise buildings and the behaviour of structural systems to resist simulated wind loading. Cam has a wealth of experience in the structural engineering field because for most of his early career, he worked as a structural engineer on a wide range of domestic, commercial and industrial projects.

\section{GEOFF BOUGHTON}

Dr Geoff Boughton the director of TimberED Services Pty Ltd, a small consultancy specialising in timber engineering. He is also an adjunct associate professor at Curtin University of Technology and previously had been a research fellow at James Cook University in the Cyclone Testing Station. Geoff has participated in a number of investigations of tropical cyclone damage both in Australia and overseas. He is a fellow of Engineers Australia and is registered on NPER. 